
for Mechanical Engineering

\title{
Calculation and analysis of meshing efficiency of composite motion of the curve-face gear pairs
}

\begin{tabular}{|r|l|}
\hline Journal: & Transactions of the Canadian Society for Mechanical Engineering \\
\hline Manuscript ID & TCSME-2018-0248.R1 \\
\hline Manuscript Type: & Article \\
\hline Date Submitted by the & $13-$ Jan-2019 \\
\hline $\begin{array}{r}\text { Complete List of Authors: } \\
\text { Keywords: }\end{array}$ & $\begin{array}{l}\text { Lin, Chao; Chongqing University } \\
\text { Xing, Qingkun; China North Vehicle Research Institute } \\
\text { Xia, Xiguang; Chongqing University } \\
\text { Tang, Pei; China North Vehicle Research Institute }\end{array}$ \\
\hline $\begin{array}{r}\text { Is the invited manuscript for } \\
\text { consideration in a Special } \\
\text { Issue? : }\end{array}$ & $\begin{array}{l}\text { Not applicable (regular submission) } \\
\text { Curvear, meshing efficiency, composite motion, control variable, }\end{array}$ \\
\hline &
\end{tabular}

\section{SCHOLARONE \\ Manuscripts}




\section{TITLE PAGE}

\section{CALCULATION AND ANALYSIS OF MESHING EFFICIENCY OF COMPOSITE MOTION OF THE CURVE-FACE GEAR PAIRS}

Chao Lin / Chongqing University / E-mail: linchao@cqu.edu.cn Wensi Liu / Chongqing University / E-mail: 201707021062@cqu.edu.cn Qingkun Xing / China North Vehicle Research Institute/ E-mail: xingqingkun@163.com Xiguang Xia: / Chongqing University / E-mail: 201707021044@cqu.edu.cn Pei Tang / China North Vehicle Research Institute /E-mail: topei@sina.cn 


\title{
CALCULATION AND ANALYSIS OF MESHING EFFICIENCY OF COMPOSITE MOTION OF THE CURVE-FACE GEAR PAIRS
}

\author{
Chao Lin ${ }^{1}$, Wensi Liu ${ }^{1}$, Qingkun Xing ${ }^{2}$, Xiguang Xia ${ }^{1}$, Pei Tang ${ }^{2}$ \\ ${ }^{1}$ The State Key Laboratory of Mechanical Transmission, Chongqing University, Chongqing, China \\ ${ }^{2}$ China north vehicle research institute, Beijing, China
}

Address: No. 174, Shapingba Zheng Street, Shapingba District, Chongqing, China

Telephone number: +8613452911958

E-mail: linchao@cqu.edu.cn

\begin{abstract}
The curve-face gear is a new type of composite motion mechanism. The calculation of meshing efficiency of composite motion is proposed in this paper. According to the gear meshing principle, the force state of the curve-face gear pairs and the motion law of the composite motion are revealed. The theoretical method of the transmission efficiency of the curve-face gear composite motion is established, and the formula to calculating transmission efficiency of compound motion of the curve-face gear pairs is obtained. Using the control variable method, the factors affecting the meshing efficiency of the curve-face gear pairs are discussed. A comprehensive experimental platform is designed. The relevant experiments are carried out. The experimental data under different conditions are obtained. The experimental data is compared with the theoretical data to verify the related inference. Finally, the related measures to increase the transmission efficiency of the curve-face gear composite motion are proposed.
\end{abstract}


Keywords: curve-face gear, meshing efficiency, composite motion, control variable, improvement measures

\section{INTRODUCTION}

As one of the most widely used parts in the industry, the gear pairs has high meshing efficiency. The curve-face gear is a new type of gear, and the curve-face gear pairs compound movement is a new type of composite transmission that combines the motion characteristics of the cam and the gear. It performs the acceleration movement along the axial direction and the rotary motion along the tangential direction.

At present, there have been many researches on curve-face gears. Lin et al. proposed the theory of curve-face gears on the basis of non-bevel gears. The principle of curve-face gear meshing was discussed and the mathematical model of curve-face gears was established (Lin C, 2013), compared with several machining methods of curve-face gears, the curve-face gear body is generated (Lin C, Fan Y, 2016), the motion law and force of the composite motion of the curveface gear pairs are analyzed (Lin C, Liu Y, 2016). Cai Zhiqin and LIN Chao ( 2018) established a dynamic model of the vibration characteristics of the curve-face gear pairs transmission. In the application of compound motion of curve-face gear pairs, Lin et al. designed the Briquetting mechanism between parallel axis by combining curve-face gear pairs with linkage mechanism (Lin Chao, 2015). In addition , Lin et al (2018) also designed a new type of piston pump with a double curve-face gear as the rotor. Besides, according to the working principle of coupling and 
the drive principle of curve-face gear, the new structure of the curve-face gear coupling was put forward (Lin Chao, Zhao Xianglu, 2016). Compared with other composite motion mechanism, the compound motion mechanism of curve-face gear pairs has the following advantages: First, compared with the hydraulic mechanical composite motion mechanism, it can reduce the size and the mass of the mechanism(Yang S, 2018). Second, since the curve-face gear pairs has only two components, it simplifies the mechanical structure compared to the gear-linkage mechanism. The shortcoming of composite motion mechanism of curve-face gear pairs are its complexity in design and difficulty in manufacture. The discussion of the meshing efficiency of the curve-face gear pairs will be one of the most important steps in its application to engineering practice.

In the research of meshing efficiency of the organization, many people at home and abroad have made corresponding contributions. Zheng Rui (2015) discussed the factors affecting the meshing efficiency of the end face cam. As for calculation of the meshing efficiency of the gear mechanism, Yu Li et al. ( 2018 ) exploring the meshing efficiency of a new type of conical involute gear using the piecewise equivalent method. Yao et al. ( 2001) used the ratio of the power to overcome the resistance to the driving power to find the mathematical formula of the instantaneous and average transmission efficiency under the condition of internal and external meshing of the spur gear, and verified the accuracy of the formula. Considering the power loss caused by the increase in gear temperature caused by hysteresis and friction, S. Kirupasankar et al (2012) found the meshing efficiency of the polyamide nanocomposite spur gear. Sheng et al. (2016) used the TCA analysis of the face gear transmission to calculate the instantaneous and average transmission efficiency of the spur gear-to-face gear pairs, and analyzed the influence of the face gear related parameters on the meshing efficiency. Cai et al ( 2017 ) studied the transmission efficiency of the nutation devices base on the transmission ratio and two-stage 
nutation drive systems parameters. Besides, he also discussed the influence of system parameters on cone displacement error and axial misalignment. As to the planetary gear train, Jose M.del Castillo (2002) used two different ways to obtain the analytical expression for the efficiency. Through the analysis of the factors affecting the transmission efficiency of the gearbox, Li Youhua et al (2017) established a theoretical analysis model of gearbox transmission efficiency in terms of power consumption.

Due to its complex motion law and force, the curve-face gear pairs has a complicated calculation method for its instantaneous and dynamic average transmission efficiency. In this paper, the ratio of useful work to total work during the compound motion of the curve-face gear pairs is used, and the influence of sliding speed and lubrication condition is neglected, which simplifies the theoretical analysis and calculation process, and the instantaneous meshing efficiency of the composite motion of the curve-face gear pairs is obtained general formula. Using the method of control variables, the influence of different parameters of the curve-face gear pairs on the meshing efficiency is studied. Finally, the relevant inferences are verified by experiments.

\section{ANALYSIS OF COMPOSITE MOTION LAW}

The curve-face gear pairs is illustrated as shown in Fig.1, the driving gear, that is, the normal spur gear. Coordinates $S_{1}\left(\mathrm{X}_{1} \mathrm{Y}_{1}\right)$ and $S_{2}\left(\mathrm{X}_{2} \mathrm{Y}_{2} \mathrm{Z}_{2}\right)$ are fixed on the spur gear and the curve-face gear. Coordinates $S_{\mathrm{m}}\left(\mathrm{X}_{m} \mathrm{Y}_{m} \mathrm{Z}_{m}\right)$ and $S_{n}\left(\mathrm{X}_{n} \mathrm{Y}_{n} \mathrm{Z}_{n}\right)$ are the accompanied coordinates system of the spur gear and the curve-face gear. The radius of the spur gear is $r$ and the radius of the curve-face gear is R. When the rotating angle of spur gear is $\theta_{1}$, the rotating angle of the curve-face gear is $\theta_{2}$, and the maximum axial displacement is $\mathrm{h}$.

According to the principle of spatial coordinate transformation, the conversion matrix 
transformed from the accompanied coordinate system $S_{m}$ on the spur gear 1 to the accompanied coordinate system $S_{n}$ on the curve-face gear 2 is:

$$
M_{n m}=M_{m 2} M_{21} M_{1 n}=\left[\begin{array}{cccc}
-\sin \theta_{1} \sin \theta_{2} & \cos \theta_{1} \sin \theta_{2} & \cos \theta_{2} & -R \cos \theta_{2} \\
-\cos \theta_{2} \sin \theta_{1} & \cos \theta_{1} \sin \theta_{2} & -\sin \theta_{2} & R \sin \theta_{2} \\
-\cos \theta_{1} & -\sin \theta_{1} & 0 & r+h \\
0 & 0 & 0 & 1
\end{array}\right]
$$

When the value of point $P_{1}$ in accompanied coordinate system $S_{m}$ can be expressed as $\left[\begin{array}{lll}r \cos \theta_{1} & r \sin \theta_{1} & 0\end{array}\right]$, and the value of point $P_{2}$ in accompanied coordinate system $S_{n}$ can be express as $\left[\begin{array}{lll}x_{n 2} & y_{n 2} & z_{n 2}\end{array}\right]$. According to the Eq.1 and the principle of spatial coordinate transformation, the value of point $P_{2}$ can be expressed as:

$$
\left[\begin{array}{c}
x_{n 2} \\
y_{n 2} \\
z_{n 2} \\
1
\end{array}\right]=M_{n m}\left[\begin{array}{c}
r \cos \theta_{1} \\
r \sin \theta_{1} \\
0 \\
1
\end{array}\right]=\left[\begin{array}{c}
-R \cos \theta_{2} \\
R \sin \theta_{2} \\
h \\
1
\end{array}\right]
$$

So that the section curve equation of the pitch curve of curve-face gear 2 can be express as:

$$
\left\{\begin{array}{c}
x_{2}=-R \cos \theta_{2} \\
y_{2}=-R \sin \theta_{2} \\
z_{2}=h
\end{array}\right.
$$

The spur gear 1 is fixed as a driving wheel, and the curve-face gear 2 is used as a driven wheel, the driven wheel output is a rotary motion and a reciprocating motion in a vertical direction.

As the Fig2 showed, the axial displacement of the curve-face gear is [Lin C, Yu Y et al 2017]:

$$
\left\{\begin{array}{c}
S=h\left(\frac{10}{\theta_{h}^{3}} \theta_{2}^{3}-\frac{15}{\theta_{h}^{4}} \theta_{2}^{4}+\frac{6}{\theta_{h}^{5}} \theta_{2}^{5}\right), 0 \leq \theta_{2} \leq \theta_{h} \\
S=h-h\left(\frac{10}{\theta_{H}^{3}} \theta_{2}^{3}-\frac{15}{\theta_{H}^{4}} \theta_{2}^{4}+\frac{6}{\theta_{H}^{5}} \theta_{2}^{5}\right), \theta_{h} \leq \theta_{2} \leq \theta_{H}
\end{array}\right.
$$

The axial velocity of the curve-face gear 2 is 


$$
\left\{\begin{array}{c}
V_{s}=h \omega_{2}\left(\frac{30}{\theta_{h}^{3}} \theta_{2}^{2}-\frac{60}{\theta_{h}^{4}} \theta_{2}^{3}+\frac{30}{\theta_{h}^{5}} \theta_{2}^{4}\right), 0 \leq \theta_{2} \leq \theta_{h} \\
V_{s}=-h \omega_{2}\left(\frac{30}{\theta_{H}^{3}}\left(\theta_{2}-\theta_{h}\right)_{2}^{2}-\frac{60}{\theta_{H}^{4}}\left(\theta_{2}-\theta_{h}\right)_{2}^{3}+\frac{30}{\theta_{H}^{5}}\left(\theta_{2}-\theta_{h}\right)_{2}^{4}\right), \theta_{h} \leq \theta_{2} \leq \theta_{H}
\end{array}\right.
$$

The axial acceleration of the curve-face gear 2 is

$$
\left\{\begin{array}{c}
a=h \omega_{2}^{2}\left(\frac{60}{\theta_{h}^{3}} \theta_{2}-\frac{180}{\theta_{h}^{4}} \theta_{2}^{2}+\frac{120}{\theta_{h}^{5}} \theta_{2}^{3}\right), 0 \leq \theta_{2} \leq \theta_{h} \\
a=-h \omega_{2}^{2}\left(\frac{60}{\theta_{H}^{3}}\left(\theta_{2}-\theta_{H}\right)-\frac{180}{\theta_{H}^{4}}\left(\theta_{2}-\theta_{H}\right)^{2}+\frac{120}{\theta_{H}^{5}}\left(\theta_{2}-\theta_{H}\right)^{3}\right), \theta_{h} \leq \theta_{2} \leq \theta_{H}
\end{array}\right.
$$

where

$\omega_{2}$ : the angular velocity of the curve-face gear 2

$\theta_{h}: \theta_{h}=\pi / n_{2}$

$\theta_{H}: \theta_{H}=2 \pi / n_{2}-\theta_{h}$

$n_{2}:$ the order of the curve-face gear 2

As the Fig 2 shown, the point $\mathrm{P}$ is the pitch point. According to the gear meshing principle, during the gear meshing process, the instantaneous speed of the two gears at the pitch point A is equal, $\quad \vec{v}_{1}=\mathbf{v}_{2}$, and $\begin{aligned} & \mathbf{u}_{1}, v_{2} \\ & v_{1}\end{aligned}$ is the speed of the normal spur gear 1 and the curve-face gear 2 respectively at the pitch point. As for the speed of the curve-face gear $2, \quad \begin{aligned} & \mathbf{u} \\ & v_{2}=v_{t}+v_{s}\end{aligned}$, and $\begin{aligned} & \mathbf{u} \\ & v_{t}, v_{s}\end{aligned}$ is the tangential speed and the axial speed of the curve-face gear 2 respectively. As for the spur gear $1, \quad \vec{v}_{1}=r \mathbf{w}_{1}$, and $\underset{\omega_{1}}{\mathbf{w}_{1}}$ is the angular velocity of the driving gear 1 . Thurs, the value of the tangential speed of the curve-face gear 2 is:

$$
\underset{v_{t}}{\mathbf{u}}=\sqrt{v_{1}^{2}-v_{s}^{2}}
$$

The transmission ratio of the curve-face gear can be express as: 


$$
i_{12}=\frac{\omega_{1}}{\omega_{2}}=\frac{1}{r} \sqrt{s^{2}+R^{2}}
$$

The angular velocity of the curve-face gear 2 is:

$$
\omega_{2}=\frac{\omega_{1}}{i_{12}}=\frac{r \omega_{1}}{\sqrt{s^{2}+R^{2}}}
$$

\section{FORCE ANALYSIS}

In the process of composite movement of the curve-face gear, if the gear pairs is to be properly meshed and continuously driven, the curve-face gear and the spur gear should always remain engaged. However, as the rotational speed of the drive gear increases, the axial movement speed of the curve-face gear also increases, it will cause the phenomenon that the curve-face gear cannot return to the initial position. In order to avoid this phenomenon, a compression spring is installed between the curve-face gear and the linear bearing, and the spring plays an auxiliary role, so that the curve-face gear can always meshes with the spur gear, and no return cannot occur.

\subsection{Force analysis of the curve-face gear}

As Fig.2 shown, the driving gear 1 is the spur gear, it was subject to radial force $F_{r 1}$ and tangential force $F_{t 1}$. The curve-face gear 2 were subject to axial force $F_{z 2}$, tangential force $F_{t 2}$ and spring force $F_{0}$. Add an idler gear to the curve-face gear to eliminate axial force imbalance.

The driving gear is the spur gear:

$$
\begin{gathered}
F_{t 1}=\frac{T_{1}}{r} \\
T_{1}=\frac{T_{2}+m_{2} a_{2}+F_{0} \mathrm{r}}{i_{12}}
\end{gathered}
$$




$$
\begin{gathered}
F_{r 1}=0.5 F_{t 1} \tan \alpha \\
F_{t 2}=-F_{t 1} \\
F_{s 2}=-F_{r 1}=0.5 F_{t 1} \tan \alpha
\end{gathered}
$$

In the above formula, $T_{1} 、 T_{2}$ is the torque of the spur gear and the curve-face gear respectively. $i_{12}$ is the transmission ratio of the curve-face gear pairs. $\alpha$ is pressure angle of composite motion. $a_{2}$ is axial acceleration of the curve-face gear.

\subsection{Pressure angle}

Get the value of pressure angle of composite motion is a key step to analyze the force condition. For the curve-face gear pairs compound movement, the pressure angle during the meshing process is different from that of the standard involute gear pairs. The angle between the direction line of any normal pressure on the involute and the direction of the point velocity is the pressure angle of the point.

As shown in Fig.2, $\vec{v}_{t} 、 v_{s}, v_{2}$ is the tangential speed, the axial speed and the velocity of the curve-face gear 2 respectively, $F_{n} 、 F_{t 2} 、 F_{s 2}$ is the normal 、tangential 、 and axial forces experienced by the curve-face gear. We set the value of pressure angle of the spur gear 1 is $\alpha_{0}=20^{\circ}$, and it will never change when the curve-face gear pairs engaging. $\beta$ is the angle between the tangential velocity $v_{t}$ and the velocity of the curve-face gear.

According to the geometric relationship shown in the Fig.4, the value of pressure angle of the curve-face gear 2 can be express as:

$$
\alpha=\alpha_{0}-\beta
$$




$$
\beta=\arctan \left(v_{s} / v_{t}\right)
$$

(17)

According to the Eqs.(5), (7), (15) and (16), we can get the expression of pressure angle of the curve-face gear 2 :

$$
\left\{\begin{array}{c}
\alpha=\alpha_{0}-\arctan \left\{\frac{h}{R}\left(\frac{30}{\theta_{h}{ }^{3}} \theta_{2}^{2}-\frac{60}{\theta_{h}{ }^{4}} \theta_{2}^{3}+\frac{30}{\theta_{h}{ }^{5}} \theta_{2}^{4}\right)\right\}, 0 \leq \theta_{2} \leq \theta_{h} \\
\alpha=\alpha_{0}-\arctan \left\{-\frac{h}{R}\left(\frac{30}{\theta_{H}{ }^{3}}\left(\theta_{2}-\theta_{h}\right)^{2}-\frac{60}{\theta_{H}{ }^{4}}\left(\theta_{2}-\theta_{h}\right)^{3}+\frac{30}{\theta_{H}{ }^{5}}\left(\theta_{2}-\theta_{h}\right)^{4}\right)\right\}, \theta_{h} \leq \theta_{2} \leq \theta_{H}
\end{array}\right.
$$

\subsection{Force analysis of spring force}

The axial reciprocating motion model of the curve-face gear pairs is shown in Figure.5. The value of the curve-face gear's quality is $m$, the spring rate coefficient is $k$, the viscous damping coefficient of the transmission system is $\mathrm{c}$, the axial displacement of the curve-face gear is s.

According to Hooke's law, the spring force $F_{0}$ can express as:

$$
F_{0}=k g(x+s)
$$

$x$ : Initial compression of the spring;

In the Eq.17, parameter $\mathrm{k}$ is spring stiffness factor, and $\mathrm{k}$ is related to the inherent properties of the spring:

$$
k=\frac{G d^{4}}{8 n D^{3}}
$$

where

G: Spring material shear modulus ( $\mathrm{MPa})$

$\mathrm{d}$ : Spring diameter ( $\mathrm{mm})$

D: Spring mid-diameter (mm)

$\mathrm{n}$ : Spring effective number of turns 


\section{INSTANTANEOUS EFFICIENCY CALCULATION AND ANALYSIS}

In the meshing process of the curve-face gear pairs composite drive, the pressure angle of the curve-face gear, the force of the gear teeth and the speed of the gear change continuously with the rotation of the gear, so the instantaneous meshing efficiency of the gear is constantly changing.

\subsection{Calculation of the instantaneous efficiency}

According to the Eqs. (5)、 (7)、(10)、(12)、(13)、 (14)、 (18) shown, we can get the value of the velocity and the force of the curve-face gear, the direction of the velocity and the force of the curve-face gear was shown in Fig. 2 and Fig. 3 respectively.

During the compound motion of the curve-face gear pairs, when the driving gear moves from the peak of the curve-face gear to the trough, the curve-face gear gradually moves upward under the reaction of the spring force, and at this time, the spring force performs the positive work on the curve-face gear. When the driving gear moves from the trough of the curve-face gear to the peak, the curve-face gear is subjected to the axial force of the spur gear, and moves downward, the spring is gradually squeezed to generate deformation, and the spring force performs negative work on the curve-face gear.

In summary, during the compound motion of the curve-face gear pairs, the power $P_{\text {in }}$ of the input total includes the power $P_{0}$ of the spring, the input power $P_{1}$ of the spur gear, and the power $P_{\text {out }}$ of the total output includes the rotational output power $P_{t}$ of the curve-face gear, and the power $P_{s}$ of axial moving output. 
Thurs the value of the instantaneous meshing efficiency of gear pairs can express as:

$$
\eta=\frac{P_{\text {out }}}{P_{\text {in }}}=\frac{P_{t}+P_{z}}{P_{0}+P_{1}}
$$

Simultaneous the Eqs.(4),(5),(18) and (19), the value of $P_{0}$ can express as:

$$
P_{0}=k(h-s) V_{s}=\frac{G d^{4}}{8 n D^{3}}(L-s) V_{s}
$$

where $\mathrm{L}$ is the value of free height of the spring.

Simultaneous the Eqs.(7), (8), and (11), the value of $P_{1}$ can express as:

$$
P_{1}=T_{1} \omega_{1}=\frac{\left(T_{2}+m_{2} a_{2}+F_{0} D / 2\right) 2 \pi N_{1}}{60 i_{12}}
$$

Simultaneous the Eqs.(7), (8), (13), (16) and (17), the value of $P_{t}$ can express as:

$$
P_{t}=F_{t 2} V_{t}=\frac{\left(T_{2}+m_{2} a_{2}+F_{0} D / 2\right) / i_{12}}{r} \frac{\omega_{2} R}{60}
$$

Simultaneous the Eqs.(5), (14), (16) and (17), the value of $P_{s}$ can express as:

$$
\left\{\begin{array}{c}
P_{s}=F_{s 2} V_{s}=0.5 F_{t 1} \tan \alpha V_{s}, 0 \leq \theta_{2} \leq \theta_{\mathrm{h}} \\
P_{s}=F_{s 2} V_{s}=0.5\left(F_{t 1}-F_{0}\right) \tan \alpha V_{s}, \theta_{\mathrm{h}} \leq \theta_{2} \leq \theta_{H}
\end{array}\right.
$$

Substituting Eqs.(21) to (24) into Eq.(20), the value of the instantaneous meshing efficiency of the curve-face gear pairs can express as: 


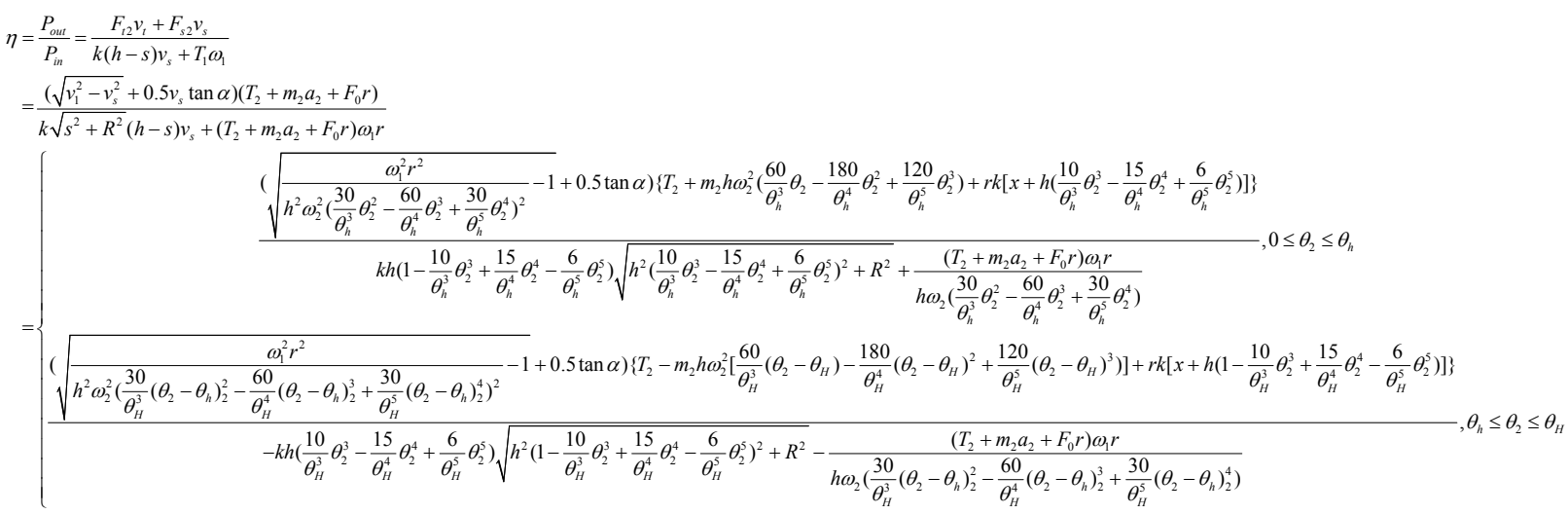

The value of the rotation efficiency of the curve-face gear pairs can express as:

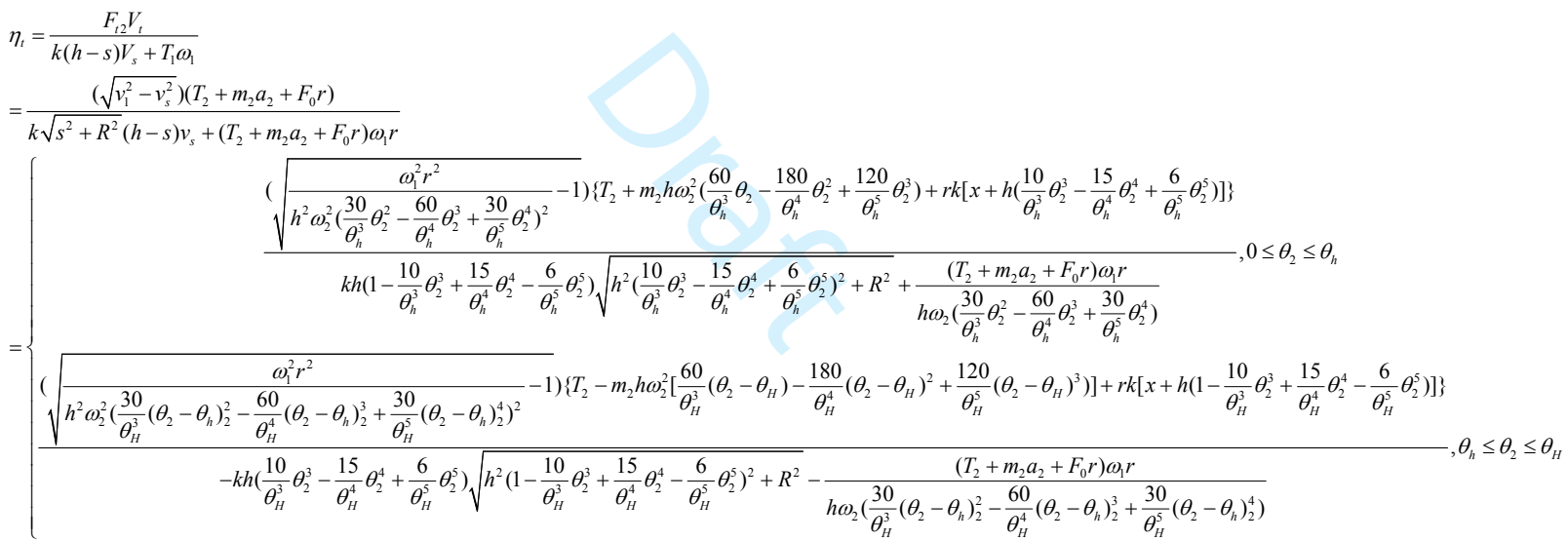

\subsection{Analysis of instantaneous efficiency}

According to GB/T $1358-2009$, take the parameter of the compressed spring as: $\mathrm{d}=4 \mathrm{~mm}$, $\mathrm{D}=45 \mathrm{~mm}, \mathrm{n}=10, \mathrm{G}=78.5 \mathrm{MPa}, \mathrm{L}=20 \mathrm{~mm}$. Take the parameter of the curve-face as: $n_{2}=2, h=10 \mathrm{~mm}, R=50 \mathrm{~mm}$. Fig 6 shown the relationship between instantaneous meshing efficiency $\eta$, axial displacement $\mathrm{S}$, axial velocity $v_{s}$ and rotating angle of the curve-face gear. 
As shown in Fig6, at point $A\left(\theta_{2}=0^{\circ}\right)$, the spur gear and the curve-face gear mesh with the peak position of the curve-face gear, and the spring is in a tight state. Point $\mathrm{A}$ is the peak of the curve-face gear, the instantaneous meshing efficiency at the peak of the curve-face gear is $\eta_{A}=0.92$. From point A to $C\left(\theta_{2}=90^{\circ}\right)$, the spring begins to gradually stretch, and under the action of the spring force, the curve-face gear gradually moves upward. At point $B\left(\theta_{2}=38.4^{\circ}\right)$ ,curve-face gear pairs instantaneous meshing efficiency is minimized, $\eta_{B}=0.88$. At point $\mathrm{C}$, the value of axial displacement of the curve-face and the elongation of the spring reaches the maximum, the axial velocity of the curve-face gear is $v_{s}=0$, curve-face gear pairs instantaneous meshing efficiency is maximum, $\eta_{C}=0.96$.

\section{INFLUENCE OF PARAMETERS ON MESHING EFFICIENCY}

According to analysis, it can be seen that the meshing efficiency is affected by the force and the velocity in the process of transmission. As well as the axial velocity and the tangential velocity, the radial force and the tangential force are both affected by the basic parameters of the curve-face gear.

According to the above equations, changing the basic parameters of the curve-face gear transmission, diagram of the meshing efficiency can be obtained. Basic parameters of the curveface gear pairs are show in Table 1 . Impacts of $n_{2}, h$ and $L$ on the meshing efficiency and rotating efficiency are discussed. The value in parentheses mean that the parameter is fixed when other parameters change.

When $n_{2}=2,3,4$, the law of the meshing efficiency $\eta$ and axial velocity of the curve-face gear $v_{s}$ are shown as Fig.7: 
The relationship between efficiency and the rotation angle of curve-face gear are shown in Fig 6. When the value of the curve-face gear's order is $n_{2}=2,3$ and 4 , the value of the dynamic average efficiency is $\bar{\eta}_{2}=0.9301, \bar{\eta}_{3}=0.9182, \bar{\eta}_{4}=0.9050 \quad$ respectively. As the order of the curve-face gear is increased, the transient meshing efficiency change period of the curve-face gear pairs becomes shorter, and the maximum value of the instantaneous meshing efficiency is constant and the minimum value is decreased, the dynamic efficiency decreases. As Fig.7 shown, the axial velocity of the curve-face gear changes within a large range of variation, with the change of the velocity direction, which belongs to the variable acceleration motion, and there is a strong rigid impact and power loss. When the curve-face gear rotates through the same angle, as the order of the curve-face gear increases, the number of sudden changes in the axial movement speed increases, and the power loss increases, so the dynamic transmission efficiency decreases.

When $h=6,8$, and 10 , the law of the meshing efficiency $\eta$ and axial velocity of the curveface gear $v_{s}$ are shown as Fig.8

The relationship between efficiency and the rotation angle of curve-face gear are shown in Fig 8 . When the value of $\mathrm{h}$ is $6 \mathrm{~mm}, 8 \mathrm{~mm}, 10 \mathrm{~mm}$, the value of the dynamic average efficiency is $\bar{\eta}_{6}=0.9142, \bar{\eta}_{8}=0.9109$, and $\bar{\eta}_{10}=0.9078$ respectively. When the maximum axial displacement of the curve-face gear increases, the maximum value of the instantaneous meshing efficiency of the curve-face gear pairs increases, the minimum value decreases, and the dynamic average transmission efficiency decreases. It can be seen from the axial velocity image that as the axial displacement of the curve-face gear increases, the axial velocity also increases, causing the vibration and impact generated by the curve-face gear pairs during the meshing process to be large, resulting in power loss. 
When $T_{2}=10 \mathrm{Ng} n, 15 \mathrm{Ng} n$ and $20 \mathrm{Ng} n$, the law of the meshing efficiency $\eta$, tangential force of the curve-face gear $F_{t}$ and axial force $F_{s}$ are shown as Fig.9.

The relationship between efficiency and the torque experienced by the curve-face gear is shown in Fig.9. When the value of $T_{2}$ is $10 \mathrm{~N} \cdot \mathrm{m}, 15 \mathrm{~N} \cdot \mathrm{m}$, and $20 \mathrm{~N} \cdot \mathrm{m}$, the value of the dynamic average efficiency is $\eta_{\overline{10}}=0.9078, \eta_{\overline{15}}=0.9403$ and $\eta_{\overline{20}}=0.9574$ respectively. When the torque applied to the curve-face gear increases, the instantaneous meshing efficiency of the curve-face gear increases and the dynamic average efficiency increases. According to the relationship between tangential force $F_{t}$, axial force $F_{s}$ and the rotation angle of the curve-face gear in Fig.9, as the torque applied to the curve-face gear increases, the value of the tangential force and the axial force are both increase. Besides, the change of the value of the torque can hardly affect the velocity. Therefore, the useful work of the output of the curve-face gear pairs is increased.

By changing the parameters in Table 1, the values of dynamic average meshing efficiency $\bar{\eta}$ and dynamic average rotational efficiency $\bar{\eta}_{t}$ in different cases are obtained, and the relationship between them is shown in Table 2 .

It can be seen from Table 2 , the ratio of dynamic average rotational efficiency $\overline{\eta_{t}}$ and dynamic average meshing efficiency $\bar{\eta}$ are more than $97 \%$, as well as Fig 10 shown, which prove that in the process of the curve-face gear pairs composite drive, the meshing motion between the teeth outputs most of the useful work. On the other hand, power loss is mainly concentrated in the process of axial motion.

\section{EXPERIMENT}


The experiment is based on the bench test platform of the curve-face gear pairs as shown in Fig.11. The drive motor 1 transmits torque to the input shaft, and an input speed torque sensor 2 is installed between the drive motor and the input shaft to measure the input speed and torque. The input shaft drives the spur gear to rotate, and the curve-face gear meshes with the spur gear to generate a combined motion of rotation/movement, and the curve-face gear rotates axially under the action of the compression spring. The output shaft is measured by the ball spline to transmit torque to the output speed torque sensor 8 , and the output torque is provided by the magnetic powder loader 9. The function parameters of the measuring apparatus are listed as Table 3.

The motor 1 is set to output a constant rotational speed, and the magnetic powder loader 9 has a constant torque. The rotational speed $N_{1}^{\prime}$ of the spur gear 5 and the received torque $T_{1}^{\prime}$ are measured by the input speed torque sensor 2, the output rotational speed $N_{2}^{\prime}$ of the curveface gear 6 and the received torque $T_{2}^{\prime}$ are measured by the output speed torque sensor 8 . The value of the experimental transmission efficiency $\eta^{\prime}$ can be express as:

$$
\eta^{\prime}=\frac{T_{2}{ }^{\prime} N_{2}{ }^{\prime}}{T_{1}{ }^{\prime} N_{1}{ }^{\prime}}
$$

Set the output speed of motor 1 to $N_{1}^{\prime}=300 \mathrm{r} / \mathrm{min}$, and change the value of the parameters shown in Table.1, the result are shown in Fig12.

As shown in Fig.12(a) and (c), when the magnetic powder loader 9 has torque is $10 \mathrm{~N} \cdot \mathrm{m}$, the experimental dynamic average meshing efficiency of the curve-face gear with the order of 3 is $\bar{\eta}_{3}=0.8319$, the experimental dynamic average meshing efficiency of the curve-face gear with 
the order of 4 is $\bar{\eta}_{4}=0.8192$. As shown in Fig.12(b) and (d), in both cases, the magnitude of the tangential force of the curve-face fluctuates around $150 \mathrm{~N}$. The experimental dynamic average transmission efficiency decreases as the order of the curve-face gear increases, which is the same as the theoretical variation.

As shown in Fig.12(a) and (e), when the order of the curve-face is 4, the dynamic meshing efficiency of the curve-face gear with a torque of $10 \mathrm{~N} \cdot \mathrm{m}$ is $\overline{\eta_{10}}=0.8194$, the dynamic meshing efficiency of the curve-face gear with a torque of $15 \mathrm{~N} \cdot \mathrm{m}$ is $\overline{\eta_{15}}=0.8598$. When the value of the torque is $T_{2}=10 \mathrm{~N} \cdot \mathrm{m}, T_{2}=15 \mathrm{~N} \cdot \mathrm{m}$, as shown in Fig. 12(b) and (f), tangential forces of the curveface fluctuate around $150 \mathrm{~N}$ and $200 \mathrm{~N}$ respectively. The experimental dynamic average transmission efficiency increased as the value of the torque subject to the curve-face gear.

As shown in Fig.12(a), (c), and (e), the transmission efficiency errors of the compound motion of the curve-face gear pairs are $9.4 \%, 9.5 \%$, and $8.6 \%$ respectively. Since there are problems such as assembly error, friction, lubrication, etc. in practice, the transmission efficiency error is in a reasonable range. The above analysis shows that the experimentally measured data is valid and also verifies the correctness of the theoretical calculation results.

\section{CONCLUSIONS}

1) The instantaneous meshing efficiency of the composite motion of the curve-face gear pairs changes with the rotation of the curve-face gear. When the axial displacement of the curveface gear reaches the maximum value, the instantaneous meshing efficiency of the composite motion of the curve-face gear pairs reaches a maximum. In the process of the curve-face gear 
pairs composite drive, the meshing motion between the teeth outputs most of the useful work, power loss is mainly concentrated in the process of axial motion.

2) When the order of the curve-face gear increases, and the maximum value of the instantaneous meshing efficiency is constant and the minimum value is decreased, the dynamic average efficiency decreases. When the maximum axial displacement of the curve-face increase, the maximum value of the instantaneous meshing efficiency of the curve-face gear pairs increases, the minimum value decreases, and the dynamic average transmission efficiency decreases. When the torque applied to the curve-face gear increases, the instantaneous meshing efficiency of the curve-face gear increases and the dynamic average efficiency increases.

3) To improving the transmission efficiency of the curve-face, we can increase the torque subject to the curve-face, decreasing the order of the curve-face gear and increase the maximum axial displacements of the curve-face gear.

4 ) Compared with other conventional composite transmission mechanisms, the transmission efficiency of the curve-face gear pairs is higher than sliding screw transmission with $30 \% \sim 50 \%$, and is similar to the transmission efficiency of the nutation transmission devices with 80\% 95\% (Cai Y et al 2017 and Zhang Li. 2018).

\section{ACKNOWLEDGMENT}

This work was supported by the National Natural Science Foundation of China (51675060); and the Fundamental Research Funds for the Central Universities (106112017CDJPT280002). This work was supported by the Equipment Pre-Research Project (NO. 3010519404). 
This work was supported by the Chongqing University Graduate Student Research Innovation Project (CYB18023).

\section{REFERENCES}

CAI, Zhiqin, LIN, Chao. 2018. Dynamic Model and Analysis of Nonlinear Vibration Characteristic of a Curve-Face Gear Drive. Strojniški vestnik - Journal of Mechanical Engineering, [S.1.], Sci. 63(3): 161-170, D0I : 10. 5545/sv-jme. 2016. 3859.

Cai Y, Yao L, Xie Z, et al. 2017. Influence analysis of system parameters on characteristics of the nutation drive with double circular arc spiral bevel gears. Forschung im Ingenieurwesen, Sci. 81(2-3): 125-133, DOI : http://dx.doi.org/10.1007/s10010-017-0245-x.

Del Castillo J M . 2002. The analytical expression of the efficiency of planetary gear trains. Mechanism \& Machine Theory, Sci. 37(2): 197-214, D0I:http://dx.doi.org/10.1016/S0094$\underline{114 X(01) 00077-5}$.

Kirupasankar S, Gurunathan C, Gnanamoorthy R. 2012. Transmission efficiency of polyamide nanocomposite spur gears. Materials \& Design, Sci. 39(39: 338-343, DOI : http://dx.doi.org/10.1016/j.matdes.2012.02.045.

Li Youhua, Li Quancai, Liu Zhongming. 2017. Analysis and Test of the Transmission Efficiency of Low Speed and Heavy Duty Gearbox. Journal of Mechanical Transmission, Sci. 41(7): 117121, DOI:10.16578/j.issn.1004.2539.2017.07.024

Lin C, Gong H, Nie N, et al. 2013. Geometry design, three-dimensional modeling and kinematic analysis of orthogonal fluctuating gear ratio face gear drive. Proceedings of Institution of Mechanical Engineers Part C Journal of Mechanical Engineering Science, Sci. 227(4): 779-793, DOI : http://dx.doi.org/10.1177/0954406212453382. 
Lin C, Fan Y, Zhang Z, et al. 2016. Additive manufacturing with secondary processing of curveface gears. International Journal of Advanced Manufacturing Technology, Sci. 86(1-4): 1-12, DOI: $10.1007 / \mathrm{s} 00170-015-8118-7$.

Lin C, Liu Y. 2016. Characteristic analysis and application of composite motion curve-face gear pairs. Journal of the Brazilian Society of Mechanical Sciences \& Engineering, Sci. 38(6): 17971804, D0I : http://dx.doi.org/10.1007/s40430-015-0432-3.

Lin Chao, He Chunjiang, Cai Zhiqin. 2015. Surface gear-connecting rod analysis and application of composite structure. Transactions of the Chinese Society of Agricultural Engineering (Transactions of the CASE), Ei. 31(20):55-61, DOI:10.11975/j.issn.1002-6819.2015.20.008.

Lin Chao, Wei Yanqun, Zhao xianglu, Wu xiaoyong. 2018. Design and Analysis of New Type of Piston Pump. Journal of Southwest Jiaotong University, Ei. 53(3): 602-609, DOI:10.3969/j.issn.0258-2724.2018.03.023

Lin Chao, Zhao Xianglu, Zeng Dong. 2016. Constructing principle and design of curved-face gear coupling. Journal of Central South University (Science and Technology), Ei. 47(11): 3707-3714, DOI: $10.11817 /$ j.issn.1672-7207.2016.11.013

Lin C, Yu Y, Hu Y. 2017. Analysis of composite motion law and force of high speed curve-face gear. Journal of Advanced Mechanical Design Systems \& Manufacturing, Sci. 11(6), DOI: $10.1299 /$ jamdsm.2017jamdsm0070

Sheng Zhaohua, Tang Jinyuan, Chen Siyu, Wang Yixinyu. 2016. Calculation and analysis of mesh efficiency about face-gear drive with spur involute pinion. Journal of Central South University (Science and Technology), Ei.47(2): 459-466. $\underline{\text { DOI: }}$ $\underline{10.11817 / j . i s s n .1672-7207.2016 .02 .015}$ 
YU, Li ;WANG, Guangjian ;ZOU, Shuaidong. 2018. The Calculation of Meshing Efficiency of a New Type of Conical Involute Gear. Strojniški vestnik - Journal of Mechanical Engineering, [S.1.], Sci.63(5): 320-330, D0I : 10.5545/sv-jme. 2016. 3843.

Yang S, Bao Y, Fan C. 2018. Full power shift method of hydro-mechanical transmission and power transition characteristics. Transactions of the Chinese Society of Agricultural Engineering, Ei.34(5): 63-72, D0I:10.11975/j. issn. 1002-6819.2018.05.009

Yao Jianchu, Chen, Yibao, Zhou Ji, Yu Jin. 2001. Research on Calculation Method of Gearing Meshing Efficiency. Chinese Journal of Mechanical Engineering, CSCD. 37(11): 18-21+27, http://www.cjmenet.com.cn/Jwk_jxgcxb/CN/Y2001/V37/I11/18.

Zheng Rui. 2015. Design and Analysis of a Opposite-rotating-shafts Engine based on End Face Cam Transmission Mechanism. thesis, Department of Mechanical Engineering. National University of Defense Technology.

Zhang Li. 2018. Design and Experimental Research on the Test Rig for Performance of Screwdriven. thesis, Department of Mechanical Engineering. Southwest Jiaotong University.

Table 1.

\begin{tabular}{ccc}
\hline$n_{2}$ & $\mathrm{~h}[\mathrm{~mm}]$ & $T_{2}[\mathrm{~N} \cdot \mathrm{m}]$ \\
\hline 4 & 10 & $10,15,20$ \\
4 & $10,8,6$ & 10 \\
$4,3,2$ & 10 & 10 \\
\hline
\end{tabular}


Table 2.

\begin{tabular}{cccc}
\hline$n_{2}, h, T_{2}$ & $\bar{\eta}$ & $\overline{\eta_{t}}$ & $\overline{\eta_{t}} / \bar{\eta}$ \\
\hline $4,10,10$ & 0.9078 & 0.8924 & $98.30 \%$ \\
$3,10,10$ & 0.9190 & 0.9077 & $98.77 \%$ \\
$2,10,10$ & 0.9287 & 0.9213 & $99.20 \%$ \\
$4,8,10$ & 0.9109 & 0.8998 & $98.78 \%$ \\
$4,6,10$ & 0.9142 & 0.9067 & $99.18 \%$ \\
$4,10,15$ & 0.9403 & 0.9190 & $97.73 \%$ \\
$4,10,20$ & 0.9574 & 0.9329 & $97.44 \%$ \\
\hline
\end{tabular}

Table 3.

\begin{tabular}{cc}
\hline Experimental apparatus & Function parameters \\
\hline Motor & Power $5.5 \mathrm{kw}$, Rated frequency $16.7 \mathrm{~Hz}$ \\
& Speed range $6000 \mathrm{RPM}$, Torque range $50 \mathrm{~N} \cdot \mathrm{m}$, \\
Input speed torque sensor & Number of teeth 1024 \\
& Speed range $5000 \mathrm{RPM}$, Torque range $200 \mathrm{~N} \cdot \mathrm{m}$, \\
Output speed torque sensor & Number of teeth 1080 \\
Magnetic powder loader & Rated torque $50 \mathrm{~N} \cdot \mathrm{m}$ \\
\hline
\end{tabular}

Table 1. parameters of the meshing efficiency

Table 2. The value of $\bar{\eta}$ and $\overline{\eta_{t}}$

Table 3. Experimental apparatus and function parameters

Fig.1. Coordinate system of curve-face gear

Fig.2 The direction of the velocity

Fig.3. Schematic diagram of the force of the gear pairs

Fig.4. Pressure angle of the composite motion of the curve-face gear pairs 
Fig.5. Axial reciprocating motion model

Fig.6. The relationship of $\eta, \mathrm{S}, v_{s}$

Fig.7 Impact of $n_{2}$ on $\eta, v_{s}$

Fig.8 Impact of h on $\eta, v_{s}$

Fig 9. Impact of $T_{2}$ on $\eta, F_{t}, F_{s}$

Fig 10. Comparison between meshing efficiency and tangential efficiency

Fig.11. The bench test platform

Fig.12. The result of the experiment about the meshing efficiency and tangential force 


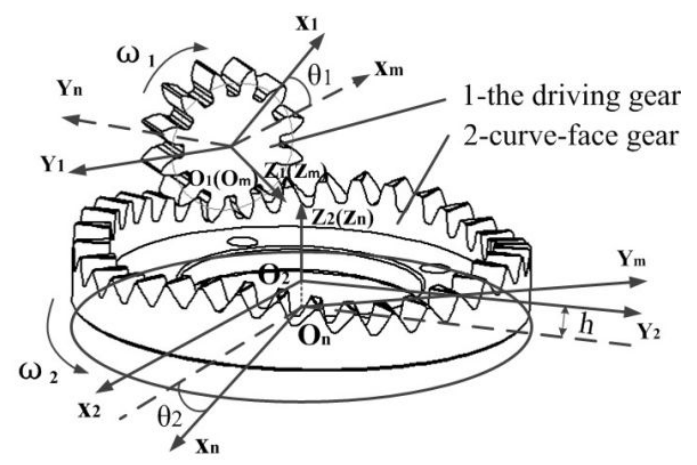

Fig1 


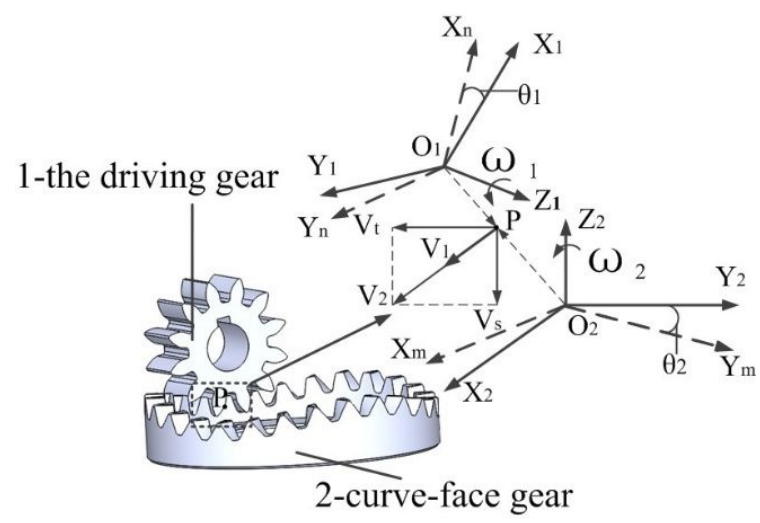

Fig2 

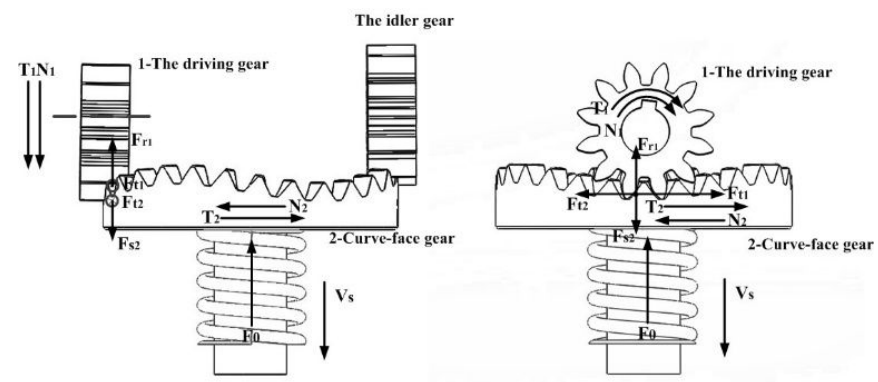

Fig3 


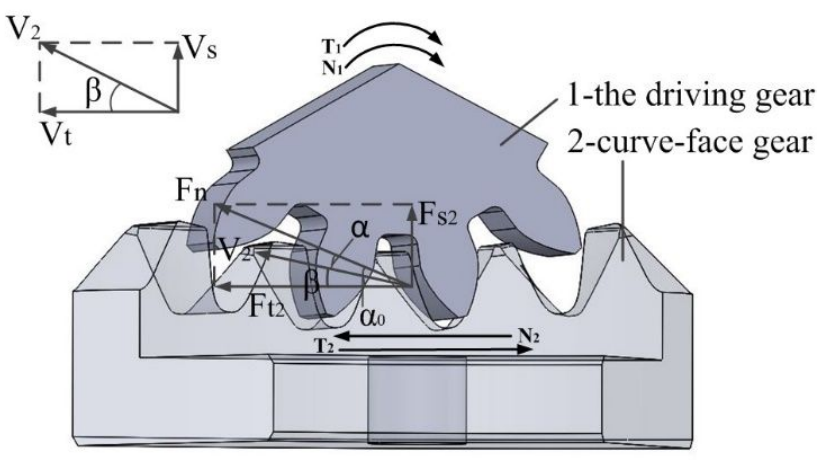

Fig4 


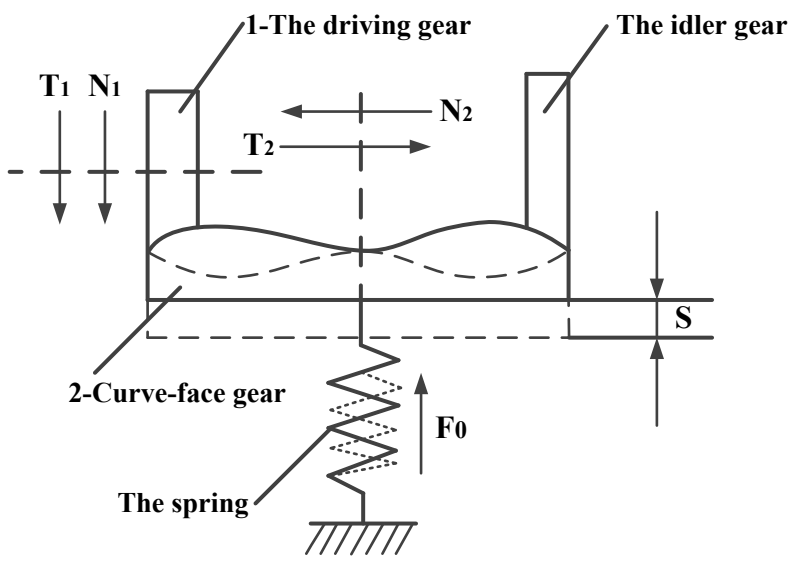

Fig5 


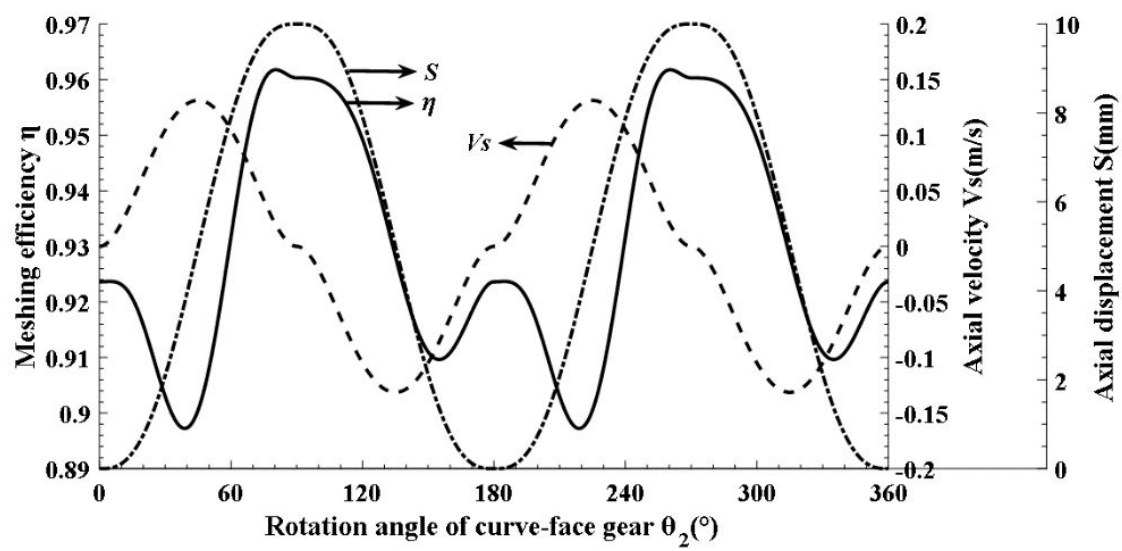

Fig6 


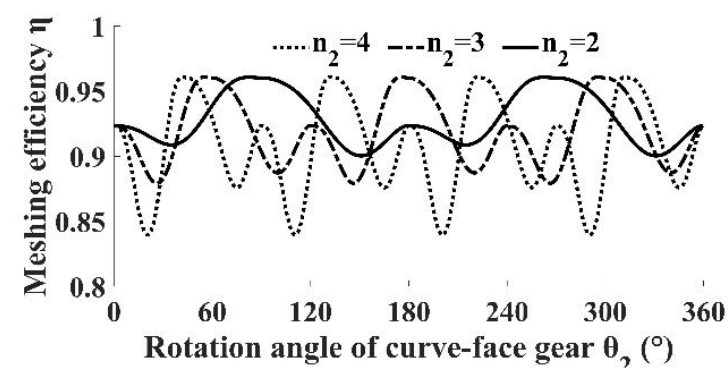

Fig7(a)

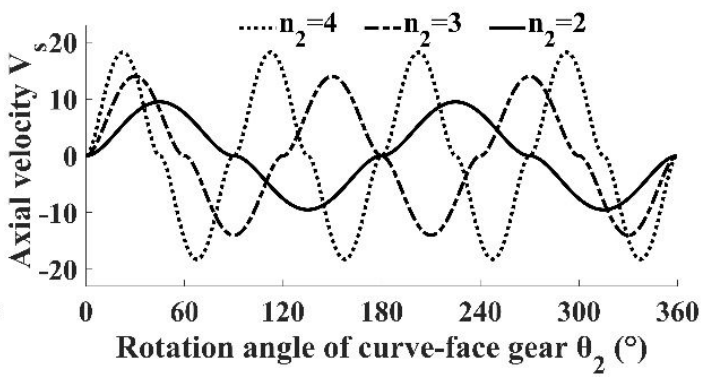

Fig7(b) 


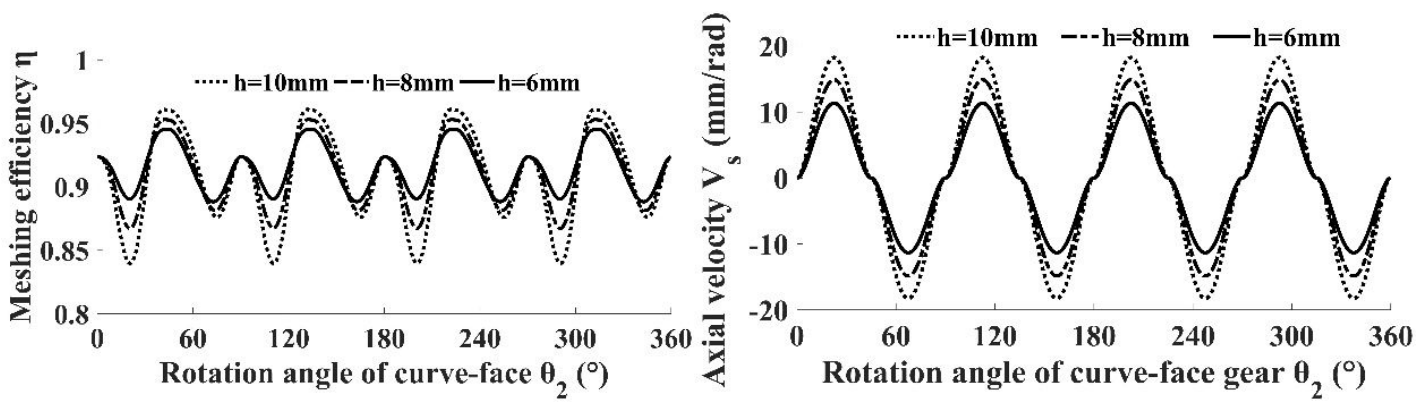

Fig8(a)

Fig8(b) 


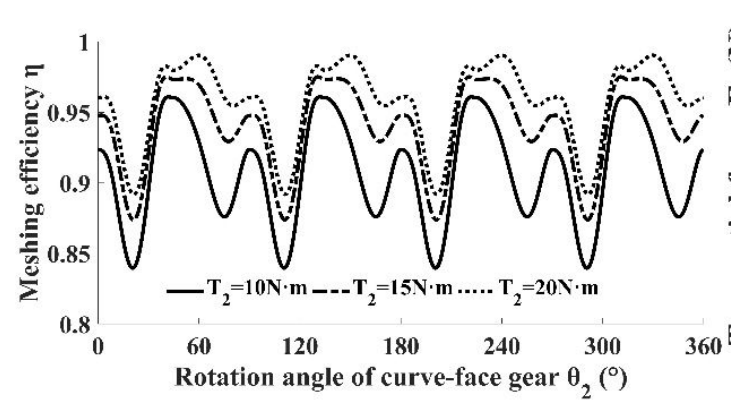

Fig9(a)

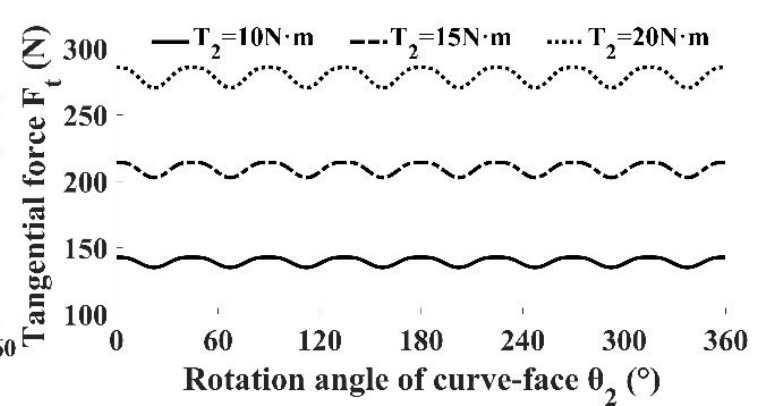

Fig9(b)

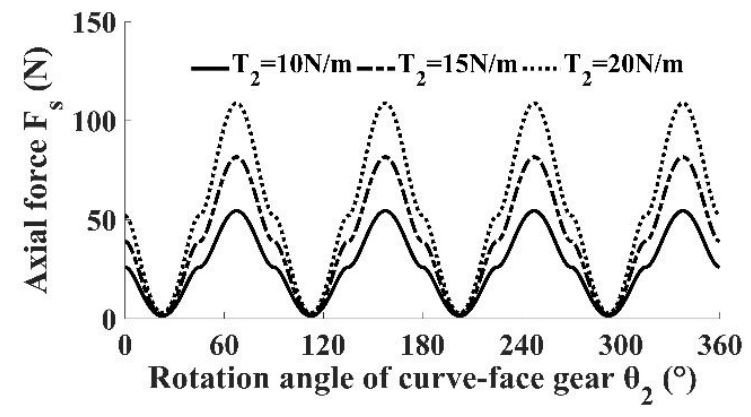

Fig9(c) 


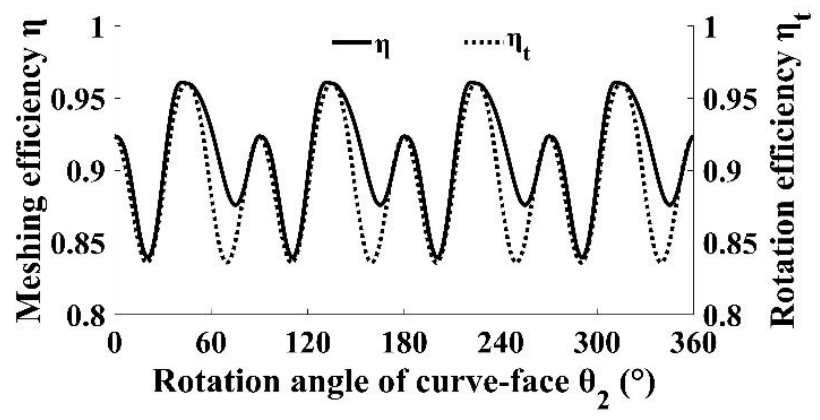

Fig10 


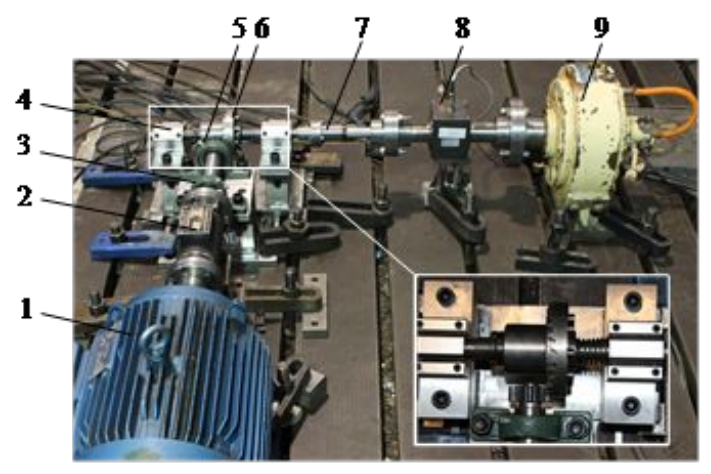

Fig11 


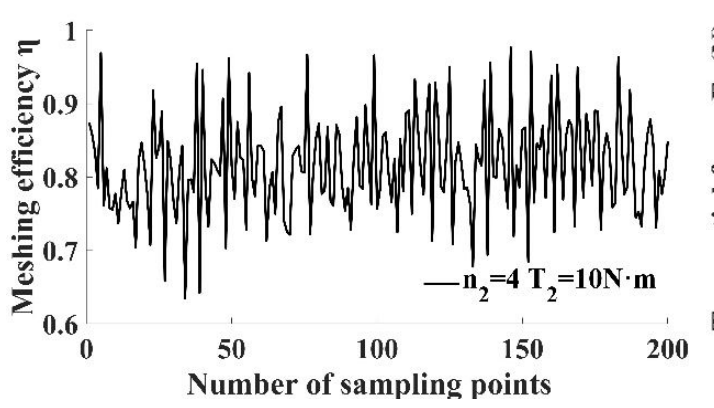

(a)

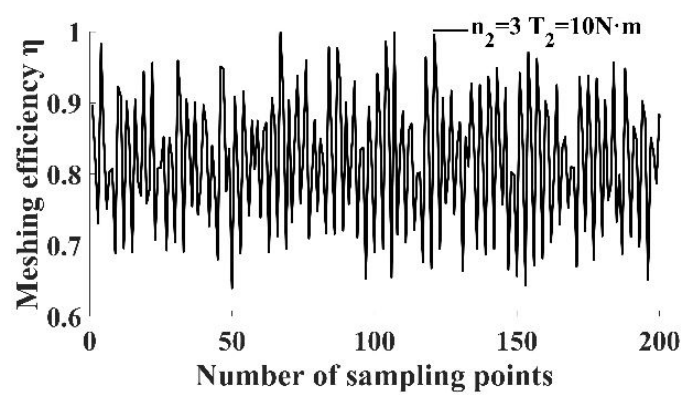

(c)

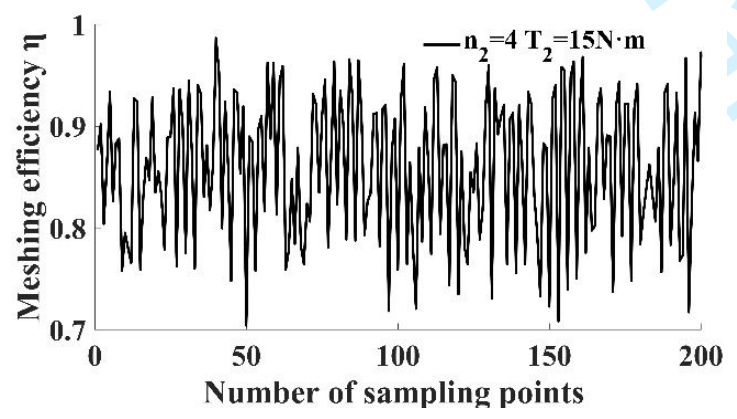

(e)

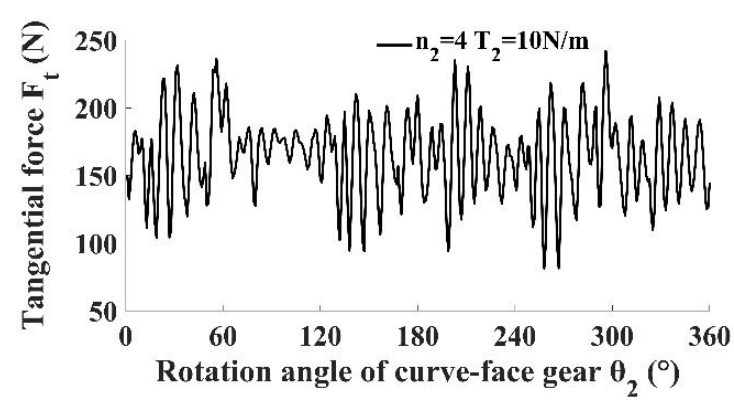

(b)

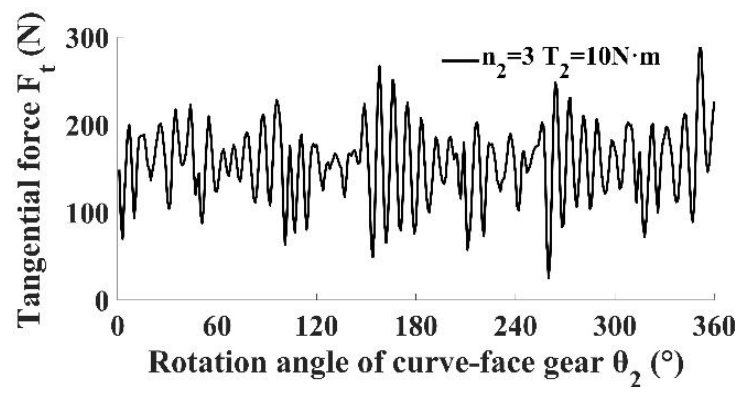

(d)

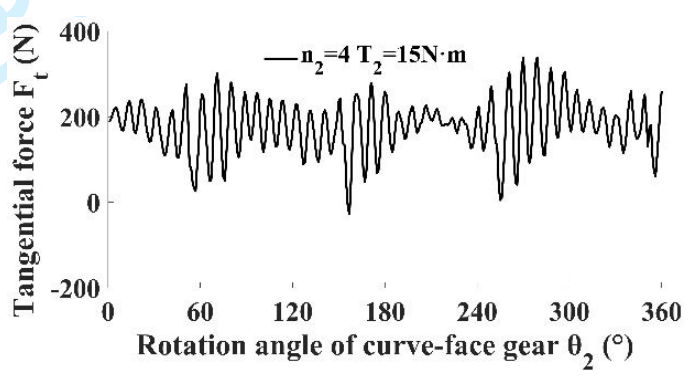

(f)

Fig12 